\title{
Elemental Quantification in Intradermal Tattoo-Inks by Means of Total Reflection X-Ray Fluorescence
}

\author{
Gabriela Riffo', Camila Ramírez-Lama1, Leonardo Bennun² \\ ${ }^{1}$ Departamento de Educación, Facultad de Educación Universidad de Concepción, Concepción, Chile \\ ${ }^{2}$ Laboratorio de Física Aplicada, Departamento de Física, Facultad de Ciencias Físicas y Matemáticas, Universidad de Concepción, \\ Concepción, Chile \\ Email: gabriffo@udec.cl, Gail.camila@gmail.com, lbennun@udec.cl
}

How to cite this paper: Riffo, G. Ramírez-Lama, C. and Bennun, L. (2020) Elemental Quantification in Intradermal Tattoo-Inks by Means of Total Reflection $\mathrm{X}$-Ray Fluorescence. Journal of Cosmetics, Dermatological Sciences and Applications, 10, 33-53.

https://doi.org/10.4236/jcdsa.2020.101005

Received: December 13, 2019

Accepted: March 22, 2020

Published: March 25, 2020

Copyright $\odot 2020$ by author(s) and Scientific Research Publishing Inc. This work is licensed under the Creative Commons Attribution International License (CC BY 4.0).

http://creativecommons.org/licenses/by/4.0/ (c) (i) Open Access

\begin{abstract}
This work describes the application of a detailed set of TXRF evaluations to the elemental content of assorted tattoo inks, on the market of the city of Concepcion, Chile. We applied TXRF as a screening method for determining the composition in 3 sets of tattoo inks, in order to establish, from an inorganic point of view, the composition and purity of the samples, evaluating their elemental innocuousness. The analyzed 48 products were freely acquired from on line suppliers. All of them were analyzed by external standard quantification, but in order to inter-compare the results, a $15 \%$ of the samples were acidly digested and then quantified by the internal standard method. In the samples we determined: 1) their inorganic quantitative composition and, 2) the possible presence of elements which are potential health hazards. In this study few anomalies were found: 1) The high presence Ti of and $\mathrm{W}$ in few samples, 2) Arsenic was found in four of them, and 3) A trace detection of a rare earth element in a particular product. The products studied are almost freely imported from a world open marked, so the questions about their innocuousness could affect not only to the Chilean society.
\end{abstract}

\section{Keywords}

Tattoo Inks Inorganic Composition, Multi-Elemental Evaluation, Trace Metal Analysis, Heavy Metals Determination, TXRF External Standard Quantification

\section{Introduction}

Tattoos can be considered as artistic, emotional and cultural expressions. This 
practice with decorative purposes has been carried out for thousands of years [1] in different cultures. In recent years, the number of tattooed people has increased significantly, especially among young people [2] [3]. Cosmetic tattoos, such as permanent eyebrow makeup, eyeliner and lip colour, have also become more popular [4]. For the latter, techniques such as micropigmentation, microblading and microshading are used.

In this work we applied TXRF as a screening technique for determining the composition in 3 sets of tattoo inks, in order to establish, from an inorganic point of view, the composition and purity of the samples, evaluating their inorganic innocuousness. The analyzed 48 products were freely acquired from on line suppliers. All of them were analyzed by external standard quantification, but in order to inter-compare the results, a $15 \%$ of the samples were acidly digested and then quantified by the internal standard method. In the samples we determined: 1) their inorganic quantitative composition and, 2) the possible presence of elements which are potential health hazards.

There are two large groups of tattoos: temporary and permanent. Hindu and Muslim religious groups often use the former, which disappear after a few weeks. The ink used is of natural origin and is known as henna. This is deposited in the upper layer of the skin (epidermis) being non-invasive for the body. In addition, many ethnic groups of the world, such as Celts, Cherokees, Incas, Mayas, and Easterners, carried out their own tattoo work, superficial or invasive [4] [5]. The people of Easter Island are an ethnic group that has persisted until now, located in the Polynesia, Chilean sovereignty.

In Chile, $17 \%$ of the population has at least one tattoo. The age range with the highest percentage of tattooed individuals is between 25 - 34 years, representing the $38 \%$ of the total. On the other hand, 1 in 10 of the Chileans that don't have tattoos has considered getting one [6].

In tattooing and permanent makeup, pigments and other components of the inks are introduced into the skin by an intradermal injection. In tattooing and micropigmentation or microshading the ink is incorporated into the dermis, while in microblading it is applied into the epidermis. This process ensures that the pigments won't be eliminated by exposing the body to the ingredients of tattoo inks in a direct and prolonged way [7].

\subsection{Tattoo Ink Composition}

Most inks consist of almost insoluble pigments dispersed in water or other solvents, plus additives such as preservatives, stabilizers, $\mathrm{pH}$ regulators, thickeners and fragrances, among others [3] [8]. Some components commonly identified in tattoo inks and permanent make up that are linked to effects on people's health are:

\subsubsection{Metals and Other Elements}

Traditionally, mercury, cobalt, chromium and manganese salts are associated with the colours red, blue, green and violet, respectively, in tattoo inks. While 
iron oxide and titanium dioxide are indicative of brown and white colors. In addition, the organic pigments and metals $(\mathrm{Al}, \mathrm{Ca}, \mathrm{Cd}$, etc.) combine to create different tones or give brightness to the colours [9] [10].

Currently, tattoo inks contain mostly organic pigments, although metals are still present, either as chromophores, shading additives or as contaminants [8]. However, micropigmentation inks in permanent makeup are still made up of inorganic pigments because of their greater stability against light and heat, their better setting capacity and their larger size, which make their removal difficult [11].

Two studies [7] [9] on the concentrations of metals in tattoo inks available in the Italian market indicated that the relative contribution of metals to the composition of the inks was highly variable, even in pigments of the same colour. They used a method of microwave digestion with acid and Sector Field Inductively Coupled Plasma Mass Spectrometry or SF-ICP-MS. The analysis of 13 tattoo inks of various colours identified the following elements in order of abundance: $\mathrm{Cr}, \mathrm{Ni}, \mathrm{Cd}, \mathrm{Co}$ and $\mathrm{Hg}$ [7]. Then, in the analysis of other 56 tattoo inks the main components were $\mathrm{Al}, \mathrm{Ba}, \mathrm{Cu}, \mathrm{Fe}$ and $\mathrm{Sr}$. Concentrations of toxic metals such as $\mathrm{Cd}, \mathrm{Mn}, \mathrm{Pb}, \mathrm{Sb}$ and $\mathrm{V}$ exceeded $1 \mu \mathrm{g} / \mathrm{g}$. Among the allergenic metals, $\mathrm{Cr}$ was the highest, followed by $\mathrm{Ni}$ and $\mathrm{Co}$ [9].

In addition, the Danish Environmental Protection Agency [12] carried out the detection of metals and other elements through a procedure of microwave digestion with acid and Mass Spectrometry with Inductively Coupled Plasma (ICP-MS). The results indicated the presence of $\mathrm{Ni}$ in all inks. While the elements $\mathrm{Be}, \mathrm{Ru}, \mathrm{Te}, \mathrm{Tb}, \mathrm{Ho}, \mathrm{Tm}$, Os or Ir were not found in any of the inks. As in Ref. [9], variable concentrations of $\mathrm{Al}$ were found in many tattoo inks and the presence of Ti associated with white inks was identified.

On its part, the Ministry of Health of New Zealand [13] analysed the amounts of heavy metals (As, Ba, Cd, Co, Cr (VI), soluble $\mathrm{Cu}, \mathrm{Hg}, \mathrm{Ni}, \mathrm{Pb}, \mathrm{Se}, \mathrm{Sb}, \mathrm{Sn}$ and $\mathrm{Zn}$ ) in 169 inks from the market. The bulk of the metals were analyzed by acid digestion in microwaves, followed by dilution and analysis by ICP-MS. The results indicated the compliance with the maximum permissible levels of heavy metals specified in N Z EPA (2012) [14]. It should be noted that Cr (VI) concentrations were below the limit of detection. Table A1 of Appendix 1 shows the maximum concentrations of metals and other elements found in tattoo inks by the studies cited above.

On the other hand, using methods of X-ray emission induced by particles or PIXE (Particle-induced X-ray emission) and scanning electron microscopy or SEM (Scanning Electron Microscope) together with energy dispersive spectroscopy or EDS (Energy dispersive X-ray spectroscopy) [15], the analysis of metal content in 226 tattoo inks available in the US market was carried out. In order of prevalence, the elements found were $\mathrm{Ti}, \mathrm{Fe}, \mathrm{Cr}, \mathrm{Cu}, \mathrm{Zr}, \mathrm{Mn}, \mathrm{Br}, \mathrm{Ni}, \mathrm{Nb}, \mathrm{Sr}, \mathrm{Zn}$, $\mathrm{Ba}, \mathrm{Mo}, \mathrm{Pb}, \mathrm{V}, \mathrm{W}$. Titanium was observed in high concentrations in almost $91 \%$ of the samples.

Also, using X-ray fluorescence spectroscopy of synchrotron radiation or 
Sy-XRF (Synchrotron Radiation X-ray Fluorescence Spectrometry), atomic absorption spectrometry and micro-Raman spectrometry, to investigate the presence of toxic elements and dangerous substances in tattoo inks levels of $\mathrm{Cr}, \mathrm{Cu}$ and $\mathrm{Pb}$ were found [16] above the limits established in the Resolution ResAP (2008) of the European Council [17].

\subsubsection{Carbon Black}

The most used colour to tattoo is black. Black inks mainly consist of carbon black or by-products of soot production [3] [8] [18].

The content of carbon black was investigated in five black tattoo inks by thermogravimetric analysis or TGA (Thermo Gravimetric Analysis). The results indicated a content of carbon black between 5.500 and $334.000 \mu \mathrm{g} / \mathrm{g}$. Greater concentration was found in black tints than in gray ones (Danish Environmental Protection Agency, 2012 [12].

Carbon black can also be used to darken other colours, therefore, some content of carbon black can be expected in colours such as green, red and blue [12]. Table A2 of Appendix 1 shows the maximum concentrations of Polycyclic Aromatic Hydrocarbons (PAHs) found in tattoo inks.

\subsubsection{Other Compounds}

Polycyclic aromatic hydrocarbons. The manufacture of carbon black involves the combustion of hydrocarbons, therefore it is possible to find PAHs (polycyclic aromatic hydrocarbons) in tattoo inks [3] [18] [19].

Primary Aromatic Amines. Primary Aromatic Amines or PAA are used in the synthesis of azo dyes and can be present in tattoo inks and permanent makeup. The Danish Environmental Protection Agency (2012) [12] carried out a quantitative analysis of the PAA content released from azo dyes in 19 tattoo inks. Some PAA content was observed in all tattoo inks investigated. Aniline and o-toluidine were found in 13 of the tattoo inks and o-anisidine in 15 tattoo inks. The analysis also determined that PAAs are present in free form and are not necessarily released from azo dyes and can be added, be a waste or a degraded product.

Ref. [19] describes the analysis of gas chromatography and mass spectrometry looking for health hazardous compounds in commercial black ink. The analysis revealed that all inks contained the softening substance dibutyl phthalate (0.12 $691 \mu \mathrm{g} / \mathrm{g})$. Some of the inks contained hexachloro-1, 3-butadiene $(0.08-4.52$ $\mu \mathrm{g} / \mathrm{g})$, methenamine $(0.08-21.64 \mu \mathrm{g} / \mathrm{g})$, dibenzofuran $(0.02-1.62 \mu \mathrm{g} / \mathrm{g})$, benzophenone $(0.26-556 \mu \mathrm{g} / \mathrm{g})$ and 9-fluorenone $(0.04-3.04 \mu \mathrm{g} / \mathrm{g})$. Some of these products can be genotoxic, cytotoxic or can generate reactive oxygen species under light exposure [10].

Meanwhile, in Ref. [18] high concentrations of phenol with values from 0.2 to $385 \mu \mathrm{g} / \mathrm{g}$ of ink were found.

In Ref. [8] prohibited substances were found in tattoo inks. They found 1, 2-benzisothiazole-3 (2H)-one, 2-octyl-4-isothiazolin-3-one, phenol, formal- 
dehyde and the strong sensitizers known as methylisothiazolinone/methylchloroisothiazolinone, generally used in cosmetics. N-Nitrosamines as N-nitrosodiethanolamine, $\mathrm{N}$-nitrosomorpholine, $\mathrm{N}$-nitrosodibutylamine and $\mathrm{N}$-nitrosodimethylamine were also found. The samples also contained $\beta$-naphtholethoxylate, nonylphenolethoxylate andoctylphenolethoxylate.

\subsection{Tattoo Removal. Exposure of Tattoo Inks to Ultraviolet and Laser Radiation}

As the number of tattooed people has increased, the demand for tattoo removal has also augmented [8]. For tattoo and permanent makeup removal, one of the most used procedures is the Q-switched laser. In this regard, there is a potential risk of splitting the pigments into toxic or carcinogenic fragments after exposure to the laser. This risk can also occur during exposure of the skin to normal light, such as sunbathing [20].

Several pigment by-products have been identified under experimental conditions of photochemical decomposition after sun exposure, ultraviolet (UV) radiation or laser. Some, such as 2-methyl-5-nitroaniline, 4-nitrotoluene, 2.5-dichloroaniline and 1, 4-dichlorobenzene could have toxic effects in human cells [10].

In Ref. [20] pyrolysis conditions were applied to mimic the ruby laser-induced decomposition of copperphthalocyanine in the blue pigment in tattoo inks. They applied gas chromatography-mass spectrometry coupled to headspace analysis (DHS-GC/MS) and bi-dimensional gas chromatography coupled to time-of-flight mass spectrometry (GCxGC-ToF-MS), identifying 1.2 benzene dicarbonitrile, benzonitrile, benzene and the poisonous gas hydrogen cyanide $(\mathrm{HCN})$ as the main fragmentation products.

It has also been proven that red pigment Red 22 absorbs UV radiation, causing its decomposition into aromatic amines [21]. On the other hand [18], it has been indicated that PAHs in tattoo inks can absorb UV radiation, generating reactive oxygen species.

\subsection{Adverse Effects Associated with Tattoo Inks}

Skin reactions. Researchers have associated the metal content in tattoo ink to allergic, eczematous, lichenoid, psudolymphomatous and granulomatous reactions [9].

Ref. [22] Reports a patient with sarcoid granulomas in the area of a black tattoo and the chemical analysis of the pigment revealed high amounts of $\mathrm{Fe}(13 \%$ $\mathrm{w} / \mathrm{w})$, Co $(14 \mu \mathrm{g} / \mathrm{g})$ and $\mathrm{Ni}(12 \mu \mathrm{g} / \mathrm{g})$. Patch tests showed a positive reaction to $\mathrm{Ni}$, Co and $\mathrm{Cd}$. Tattoo inks containing $\mathrm{Al}$ and $\mathrm{Ti}$ can also induce granulomatous reactions [7].

In ancient tattoos, metals such as mercury sulfide (red pigment, cinnabar), cobalt and its salts (blue), chromium (green), cadmium (yellow, red) and magnesium (violet) were identified as allergens [23]. On the other hand, it has been reported that mercury together with chromium and cobalt are contact sensitizers 
with various types of skin reactions in tattooed areas. In particular, red pigments that include mercury (cinnabar) can produce a delayed hypersensitivity reaction [24].

On the other hand, $80 \%$ of the allergologically most relevant red dyes in tattoo inks and permanent makeup are organic. More than $60 \%$ of them are monoazo compounds [25].

\subsection{Carcinogenic Potential}

Regarding the carcinogenic potential, tattoo inks have not been evaluated by the International Agency for Research on Cancer, IARC, although some components of the inks have been classified [26].

Cadmium and its compounds are classified as carcinogenic in humans and it is considered that the critical effects in relation to the tattoo are on the bones and kidneys. In addition, nickel is classified as a carcinogen and cutaneous sensitization is considered a critical effect (Danish Environmental Protection Agency, 2012) [12]. Cobalt and Cobalt compounds, as well as Titanium dioxide, are classified in Group 2B (possibly carcinogenic to humans) (IARC, 2018).

The composition of the inks has changed and nowadays it is less likely to find metals in tattoo inks. These have been displaced by organic dyes. Currently, most inks available on the market contain polycyclic compounds or azo pigments. Some of the PAHs and PAAs released from azo pigments found in tattoo inks have been classified as carcinogenic.

Carbon black, present in black inks, is considered a potential carcinogen (group 2B) due to its high reactivity and black inks are possibly transported to the human body through the lymphatic system, together with PAHs [18] [19]. Regarding PAHs, their critical effect in relation to tattooing is the carcinogenic potential [26].

The decomposition of azo dyes in skin tissue forms PAA that are catalyzed by solar radiation, laser treatment, or pyrolysis. In this case, the carcinogenic effect is considered critical [26]. Among these compounds, anisidine is classified as a carcinogen for humans (Group 1), Nitro-o-toluidine and Chloro-o-toluidine as a probable carcinogen (Group 2A) and 3, 3-dichlorobenzidine as a possible carcinogen (Group 2B). (IARC, 2018) [27].

Table A3 of Appendix 1 shows the classification of different components found in tattoo inks, where Group 1 corresponds to carcinogen for humans, Group 2A, probable carcinogen and Group 2B, possible carcinogen.

\section{Other Adverse Effects}

As indicated above, some of the PAHs contained in black tattoo inks can absorb UV radiation and generate reactive oxygen species, such as singlet oxygen. This singlet oxygen damages the cellular structure by oxidation of lipids and proteins, having a cytotoxic effect [18].

On the other hand, the phenol found in tattoo inks and permanent makeup is toxic and can damage the kidneys and the central nervous system. It is also clas- 
sified as teratogenic and carcinogenic [18].

\subsection{Regulation of Ink Composition}

In 2003 and 2008, the European Commission published guidelines on the chemical composition of tattoo inks. These recommendations were adopted by countries such as Belgium, France, Germany, the Netherlands, Spain and Sweden in modified versions. Other European countries regulate tattooing practices and the innocuousness of facilities in terms of health and hygiene [28].

The New Zealand Environmental Protection Agency also developed guidelines for tattoo and permanent makeup substances.

Meanwhile, in the United States tattoo inks are regulated as cosmetics and the pigments used in them, as colour additives. When they are considered cosmetic, a pre-market review or approval of tattoo inks is not required. On the contrary, color additives require the submission of a request to establish their innocuousness. So far, the Food and Drug Administration (FDA) has not exercised its regulatory authority for color additives in tattoo inks and their pigments, due to their historical use and the low number of adverse events reported [8].

In this way, Resolution ResAP (2008) 1 is the most detailed normative document that establishes requirements and criteria for the security of tattoos and permanent makeup. This recommends a maximum concentration of polycyclic aromatic hydrocarbons (PAH) in tattoo inks of 0.5 ppm. For the Benzo (a) pyrene, the limit is stricter, corresponding to $5 \mathrm{ppb}$. It also lists primary aromatic amines (PAA) that should not exist in tattoo inks, nor be released fromazo dyes. Regarding metals, it indicates maximum allowed concentrations of impurities in products for tattoos and permanent makeup, limits that are presented in Table A4 of Appendix 1. It highlights the limit associated with nickel which must be "as low as technically possible" due to its high allergenic potential.

In Denmark, there is no particular regulation in regards to the chemical substances used in tattoos. But there is a regularization of chemical products according to the provisions of the Danish Working Environment Service, which states that there should not be a greater amount than $0.1 \%$ of a carcinogenic element in a substance. This should also apply to tattoo inks (Chemical Substances in Tattoo Ink Survey of chemical substances in consumer products (Kortlægningafkemiskestoffer and forbrugerprodukter) no. 116, 2012) [12].

In the US, the FDA classifies tattoo inks as cosmetics [29].

In Chile, it is the MINSAL (Ministry of Health) that regulates the use of dyes used in pharmaceutical products and cosmetics ("List of Permitted Dyes in Pharmaceutical and Cosmetic Products, Supreme Decree 31", January 13, 2012) [30]. Also, article $n^{\circ} 9$ of Decree 304: APPROVES REGULATIONS OF TATTOO AND SIMILAR PRACTICES, 2003, provided by the MINSAL specifies that the inks used in tattoos should not have toxic components, in addition, these should be included on the list mentioned above.

Despite the high number of tattooed people, the composition of tattoo inks, 
their pharmacokinetics in the human body and the potential risks of inks are insufficiently known [3] [8]. Due to the above, its study and characterization acquire vital importance. In the present study we found some anomalies in the samples. Since the analysed products are almost freely imported from a world open marked, so the questions about their innocuousness aspects could affect not only to the Chilean society. Nowadays there is a huge expansion of products and services, so in many cases the regulatory organisations do not have the required information to define legal aspects linked to these new products, nor the infrastructure to control the correct application of the new norms. These guidelines may include the governmental management for import, export inspection, and certification systems for instance, tattoo inks. Also could be included the concern for giving the correct information to the common users, in order to prevent health problems.

\section{Theory}

\section{Total Reflection X-ray Fluorescence}

If the dry residue of the specimen is obtained with uniform distribution and minimum height, then the basic equation for TXRF [31] can be expressed as:

$$
I_{i}=K_{i} I_{0} N_{0} \sigma_{i} w_{i} m_{i} A_{i}
$$

Being $I_{i}$ the intensity of the signal produced by the $i$ element. It is described based on the following parameters: $K_{i}$, a constant that depends on the geometric factors and on the detection efficiency of the energy of the considered line; $I_{0}$ is the intensity of the excitement source, $N_{0}$, the Avogadro's number, $m_{i}$, the superficial density of the $i$ element with the atomic number $Z_{i}$ and atomic mass $A_{i}$; $\sigma_{i}$ is the cross section of the atom (scattering), and $\omega_{i}$ the fluorescence performance.

Due to the sample solution is not homogeneously deposited on the reflector, changes in the distributions of $m_{i}$ are produced, so just one sample can show significant variations of the total of counts in different spectra. To avoid this uncertainty, an internal pattern (STD) is added to the solution. It must be an element that originally is not present in the sample, and whose concentration is well defined. In the data processing, the concentrations of the original elements are referred to the concentration of the included standard. The relationship between the relative intensity of the element $S T D$ with respect to each one of the elements $i$ in the sample, can be expressed as:

$$
\frac{I_{S T D}}{I_{i}}=\frac{K_{S T D} I_{0} N_{0} \sigma_{S T D} w_{S T D} A_{S T D}}{K_{i} I_{0} N_{0} \sigma_{i} w_{i} A_{i}} \cdot \frac{m_{S T D}}{m_{i}}
$$

Due to the relation of $m_{S T D} / m_{i}$ is the same as the relation between the concentrations of these elements in the solution $\left(C_{S D T} / C_{i}\right)$, the Equation (2) can be written as [32]:

$$
\frac{I_{S T D}}{I_{i}}=S_{S T D / i} \cdot \frac{m_{S T D}}{m_{i}}=S_{S T D / i} \cdot \frac{C_{S T D}}{C_{i}}
$$


where $S_{S T D / i}$ is the relative sensitivity of the element $i$ related to the internal standard, STD. This relationship that is obtained from the sensitivity of detection of an element $i$ contained in the main equation as:

$$
S_{i}=K_{i} I_{0} N_{0} \sigma_{i} w_{i} A_{i}
$$

The sensitivity $S_{i}$ is different for each element and mainly depends on the fundamental parameters $\left(\sigma_{i}\right.$ and $\left.\omega_{i}\right)$ and the conditions of measurement $\left(K_{i}\right)$ that generally can be supposed as constants. Generally, the $S_{i}$ vs $Z$ curve is obtained measuring certificated multi-element samples and in recent works, measuring this answer when analyzing the relative intensities of compounds with well-known stoichiometries and high purity [33] [34].

In summary, the conversion from the measured intensities into the elemental concentrations is one of the most important steps in the TXRF analysis. The addition of an internal pattern, with known concentration leads to a procedure of simple quantification, in the following way:

1) To measure the intensity of the element $I_{i}$ and the intensity of the internal pattern $I_{S T D}$.

2) Determine the concentration of unknown element $C_{i}$ using the relation obtained from the Equation (2).

$$
C_{i}=\frac{I_{i}}{I_{S T D}} \cdot \frac{C_{S T D}}{S_{S T D / i}}
$$

The intensity $I_{S T D}$ and the concentration $C_{S T D}$ were previously defined.

\section{Methodology}

\subsection{Experimental}

$\mathrm{X}$-ray Spectrometer. The TXRF instrument used in this study was a S2 Picofox Bruker spectrometer enclosed in an X-ray biological shield. The system includes an X-ray metal-ceramic tube with a molybdenum target operating at $50 \mathrm{~W}$ of maximum power, at $50 \mathrm{kV}$ and $1 \mathrm{~mA}$. The system is air-cooled; and includes a multilayer monochromator; a Peltier-cooled high resolution X-Flash silicon drift detector (without liquid nitrogen cooling) with a $30 \mathrm{~mm}^{2}$ active area and an energy resolution less than $140 \mathrm{eV}$ at $100 \mathrm{kcps}$ (Mn Ka line, $5.895 \mathrm{keV}$ ). The instrument was controlled by a computer by its Spectra 6.3 software.

\subsection{Reagents}

For the calibration of the TXRF spectrometer, eight MERCK ICP single element standard solutions of $\mathrm{S}, \mathrm{K}, \mathrm{Sc}, \mathrm{V}, \mathrm{Mn}, \mathrm{Co}, \mathrm{Cu}$ and $\mathrm{Ga}$ were used. For the sample preparation as well as for the dilution of the samples, pure water was obtained from a feeder 55 WG with subsequent de-ionization by a Milli-Q SP Reagent Water System (Millipore) which yields ultrapure water with specific resistivity of $18 \mathrm{M} \Omega \cdot \mathrm{cm}$. For the ink samples acid digestion MERCK concentrated supra-pure $\mathrm{HNO}_{3}$ mineral acid was used. 


\subsection{Sample Preparation}

For the determination of elemental X-ray line sensitivities for S, K, Sc, V, Mn, $\mathrm{Co}$ and $\mathrm{Cu}$, two Multi-Element Solution (MES) standards having elemental concentration of 5 and $10 \mu \mathrm{g} / \mathrm{mL}$ were prepared by mixing the corresponding MERCK single element standards and diluting the resultant solution mixture to the required concentrations, using $\sim 1 \mathrm{M}$ nitric acid. Galium was added as internal standard in these solutions with a constant concentration of $5 \mu \mathrm{g} / \mathrm{mL}$. The TXRF spectra of these standards were measured for $500 \mathrm{~s}$ and the relative sensitivities with respect to Ga were determined, as is described in our previous studies [33] [34].

We have analyzed 48 different tattoo inks, which were acquired freely from on line suppliers, from Concepcion City, Chile. The samples can be classified in addition to colour in three different types, water based, oily based and alcohol based tattoo inks.

The $15 \%$ of these samples were digested with MERCK concentrated supra-pure $\mathrm{HNO}_{3}$ mineral acid. All of these samples were digested utilizing $5 \mathrm{~mL}$ concentrated $\mathrm{HNO}_{3}$ mineral acid, in a hot plate at $75^{\circ} \mathrm{C}$, for about 24 hours, in order to completely transfer the analytes to the homogeneous liquid samples. Vanadium was added as internal standard in these solutions with a constant concentration of $5 \mu \mathrm{g} / \mathrm{mL}$. For the preparation of the blank samples, all the above steps were followed except that milli-Q water was taken in place of the tattoo inks at the beginning of the process.

The $100 \%$ of the samples were analyzed by external standard quantification. Samples were homogenized by mechanical agitation at least for 5 minutes, then the specimens were obtained from $2 \mu \mathrm{L}$ of a single droplet. Later a $2 \mu \mathrm{L}$ of a droplet of $\mathrm{Ga}$ at $5 \mu \mathrm{g} / \mathrm{mL}$ was added directly over to the sample holder. The very-small volumes of the droplets were chosen in order to reduce effects over the morphology of the sample [35] and effects over the excitation source [36]. We replicated the methodology previously applied for Cobalt evaluation in injectable multivitamins [37], obtaining in this case uncertainties in the order of 10\%. A flow chart for the ink samples preparation is depicted in Figure 1.

The residues of the samples were obtained by heating. In all cases the TXRF spectra were acquired for $500 \mathrm{~s}$. In all measurements, the dead time of the acquisition was controlled, to be in the range 3\% - 6\%. A detailed energy calibration of the spectrometer was made after 20 measurements.

The sources that affect the quality in a TXRF evaluation are described in the Figure 2, as is described in Ref. [38], where also are included sources influencing the right function of the electronic chain of detection. In this category we can mention the dead time, the correct energy calibration of the spectrum, and also electronic settings could be included, like a correct poles/zero calibration, etc. In particular, the impact of the dead time over a TXRF (or any spectroscopic) measurement is very difficult to evaluate, from empirical methods or by mathematical theoretical formulations. 


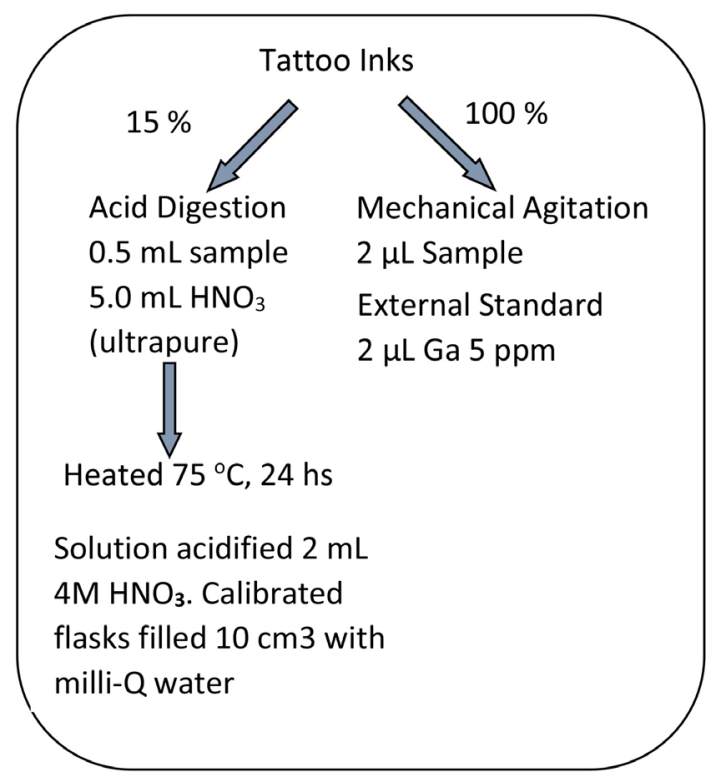

Figure 1. Flow chart of the tattoo ink samples preparation steps for their TXRF analysis.

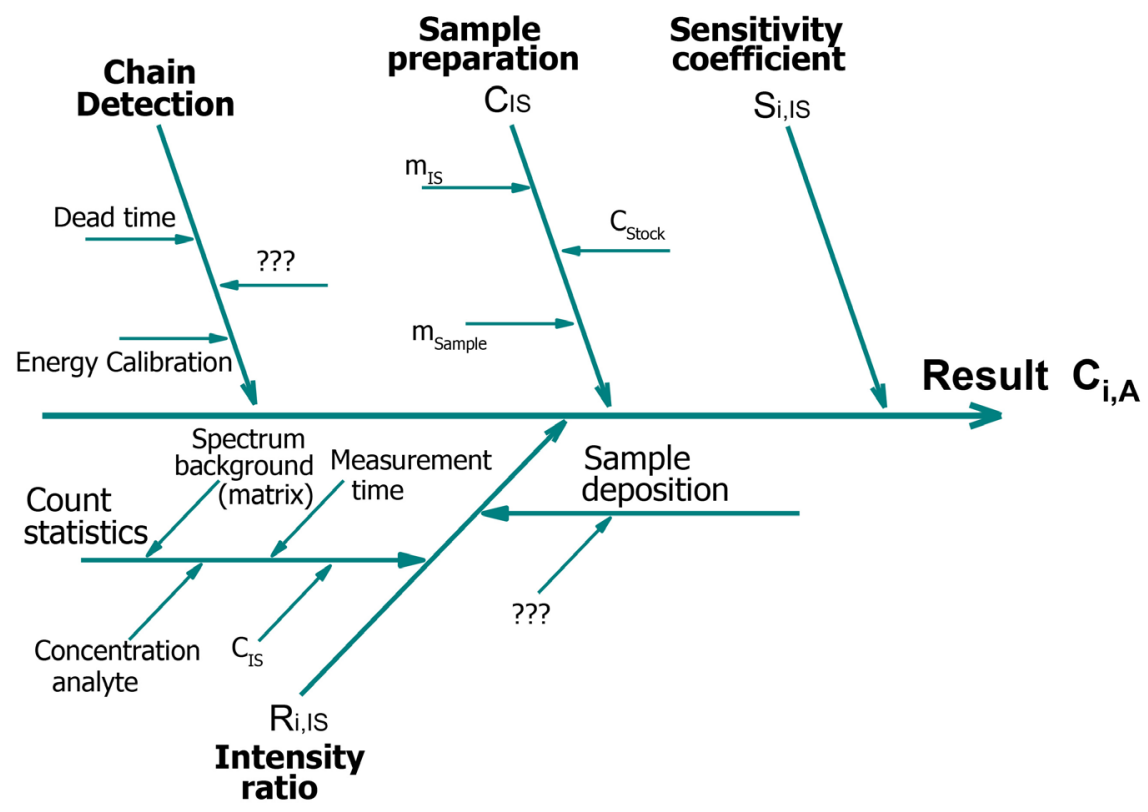

Figure 2. A four categories groups of potential factors, which affect the quality in TXRF results.

\section{Results}

The Spectra 6.3 software, released by Bruker, was used for the spectral fitting and quantification of the acquired TXRF spectra. The counts vs energy (keV) were processed with very good fitting parameters and were used to analyze the main elements present in the samples. The previously obtained sensitivity for the analytical X-ray lines were used in order to quantify the elemental abundance.

The multi-elemental results obtained for $\mathrm{Cl}, \mathrm{K}, \mathrm{Ca}, \mathrm{Ti}, \mathrm{V}, \mathrm{Cr}, \mathrm{Mn}$ and $\mathrm{Fe}$, in $\mathrm{mg} / \mathrm{L}$, for the first set of 28 tattoo inks, are shown in Table 1 . For the rest of the 
Table 1. Main elements determined by TXRF analysis, by external standard quantification, from the first set of tattoo inks. Results marked with an asterisk were obtained from acid digestion followed by internal standard quantification.

\begin{tabular}{|c|c|c|c|c|c|c|c|c|}
\hline $\begin{array}{c}\text { Sample } \\
\text { (Number) }\end{array}$ & $\mathrm{Cl}[\mathrm{mg} / \mathrm{L}]$ & $\mathrm{K}[\mathrm{mg} / \mathrm{L}]$ & $\begin{array}{c}\mathrm{Ca} \\
{[\mathrm{mg} / \mathrm{L}]}\end{array}$ & $\mathrm{Ti}[\mathrm{mg} / \mathrm{L}]$ & $\mathrm{V}[\mathrm{mg} / \mathrm{L}]$ & $\mathrm{Cr}[\mathrm{mg} / \mathrm{L}]$ & $\begin{array}{c}\mathrm{Mn} \\
{[\mathrm{mg} / \mathrm{L}]}\end{array}$ & $\mathrm{Fe}[\mathrm{mg} / \mathrm{L}]$ \\
\hline 1 & 5188 & 59.3 & 1789 & 98 & - & 1. & 1 & 258 \\
\hline 2 & 63 & 18. & 743 & 875 & - & 7 & 35 & 260 \\
\hline 3 & 2232 & 22 & 1097 & 122 & - & 7 & 1 & 203 \\
\hline $3^{*}$ & 2049 & 20.4 & 987 & 134 & & 6.7 & 0.89 & 215 \\
\hline 4 & 2859 & 41 & 2302 & 2514 & - & - & 0.7 & 285 \\
\hline 5 & 458 & 22 & 580 & 50 & - & 1 & 0.8 & 171 \\
\hline 6 & 50 & 26.7 & 689 & 13 & - & 0.4 & 0.4 & 109 \\
\hline 7 & 98 & 23 & 1413 & 137 & - & 0.6 & 0.9 & 183 \\
\hline $7^{*}$ & 112 & 24.8 & 1315 & 148 & & 0.65 & 0.84 & 193 \\
\hline 8 & 454 & 9.8 & 1407 & 3054 & 1.5 & - & - & 99 \\
\hline 9 & 205 & 19 & 555 & 1044 & - & - & 1.8 & 48 \\
\hline 10 & 203 & 42 & 1670 & 959 & - & - & 1.1 & 253 \\
\hline $10^{*}$ & 198 & 48.5 & 1788 & 1126 & & & 1.0 & 236 \\
\hline 11 & Not det. & 21 & 2024 & 37 & - & 0.7 & 0.6 & 144 \\
\hline 12 & 259 & 77 & 1699 & 117 & - & 1 & 1.4 & 564 \\
\hline 13 & 2119 & 21 & 671 & 895 & - & 0.2 & 0.4 & 82 \\
\hline 14 & 1329 & 44 & 1588 & 3043 & - & - & - & 218 \\
\hline 15 & 1504 & 40 & 1553 & 3302 & - & - & - & 203 \\
\hline 16 & 16095 & 10 & 1376 & 8 & 0.3 & 0.3 & 0.8 & 36 \\
\hline 17 & 9.3 & 71 & 980 & 23 & - & 3.6 & 2.6 & 262 \\
\hline 18 & 500 & 28 & 1258 & 1429 & - & - & - & 108 \\
\hline 19 & 148 & 14 & 431 & 17 & - & 0.1 & 0.4 & 67 \\
\hline $19^{*}$ & 157 & 15.6 & 389 & 16 & & 0.08 & 0.35 & 73 \\
\hline 20 & 1732 & 41 & 1011 & 48 &.- & 0.7 & 0.8 & 161 \\
\hline 21 & 1950 & 46 & 1920 & 952 & - & 1.2 & 1.3 & 258 \\
\hline 22 & 2394 & 21 & 2270 & 1123 & - & - & 0.7 & 178 \\
\hline 23 & 74 & 18 & 605 & 842 & - & 9 & 29 & 269 \\
\hline 24 & 1442 & 37 & 1550 & 497 & - & 1 & 1.4 & 334 \\
\hline 25 & 596 & 56 & 1816 & 2604 & - & - & 1.3 & 251 \\
\hline 26 & 712 & 55 & 2900 & 976 & - & - & 2.3 & 364 \\
\hline $26^{*}$ & 781 & 47 & 3220 & 968 & & & 2.05 & 316 \\
\hline 27 & 122 & 26 & 713 & 101 & - & 0.6 & 0.5 & 134 \\
\hline 28 & 1921 & 25 & 1569 & 831 & - & 0.7 & 1.1 & 209 \\
\hline
\end{tabular}

samples, S, Cl, K, Ca, Ti, Cr, Fe, Cu, Zn, As, W, Rb, Sr, Zr, Ba and $\mathrm{Hf}$ (in two cases) were evaluated. These results are shown in Table 2. All samples were 
Table 2. Main elements determined by TXRF analysis, by external standard quantification, from the second set of tattoo inks. Results are expressed in $\mathrm{mg} / \mathrm{L}$. Results marked with an asterisk were obtained from acid digestion followed by internal standard quantification.

\begin{tabular}{|c|c|c|c|c|c|c|c|c|c|c|c|c|c|c|c|c|}
\hline Sample & $S$ & $\mathrm{Cl}$ & K & $\mathrm{Ca}$ & $\mathrm{Ti}$ & $\mathrm{Cr}$ & $\mathrm{Fe}$ & $\mathrm{Cu}$ & $\mathrm{Zn}$ & As & W & $\mathrm{Rb}$ & $\mathrm{Sr}$ & $\mathrm{Zr}$ & $\mathrm{Ba}$ & $\mathrm{Hf}$ \\
\hline 29 & 41 & 2097 & & 310 & 353 & 2.1 & 158 & & 13 & & & & & & & \\
\hline 30 & & & & 669 & 2602 & & 224 & & 52 & 23 & & & & & & 152 \\
\hline 31 & & & & 1266 & 1781 & & 177 & & 153 & 5.8 & & & & 871 & & \\
\hline 32 & & 238 & & 344 & 247 & & 37 & 4323 & & & & & & & & \\
\hline $32^{*}$ & & 216 & & 386 & 228 & & 35 & 3828 & & & & & & & & \\
\hline 33 & 741 & 317 & 262 & 786 & & & 239 & & 37 & & 45 & & & & 53.2 & \\
\hline 34 & & & & 47 & & 8.9 & 36 & & & & & & & & & \\
\hline 35 & & 1803 & & 1645 & 1634 & & 357 & 2178 & 128 & & & & & & & \\
\hline 36 & & 79 & 248 & 189 & 278 & & 261 & 5.6 & 21 & 1.7 & & & 123 & & & \\
\hline 37 & 4118 & 72 & 1139 & 1021 & & 39.2 & 244 & 43 & 16 & & & & & & & \\
\hline 38 & & 3229 & & 5076 & 330 & & 191 & 2939 & & & & & 953 & & & \\
\hline $38^{*}$ & & 3009 & & 4813 & 368 & & 180 & 3223 & & & & & & & & \\
\hline 39 & & 484 & & 1280 & & & 18 & & 38 & & & & 1392 & 957 & 28.3 & 0.23 \\
\hline 40 & & 907 & & 1867 & 815 & & 383 & 1758 & 125 & & & & & & & \\
\hline 41 & & 2208 & & 978 & & & 117 & 674 & 38 & & & 39.6 & 745 & & 302 & \\
\hline 42 & & & & 1419 & 847 & & 626 & 1535 & & & 581 & & & & & \\
\hline 43 & & 2767 & & 643 & 1429 & & 72 & 262 & 37.5 & 2.4 & 783 & & & 5392 & & \\
\hline 44 & & & & 151 & 1281 & & 12 & & 9.7 & 1.1 & 945 & & 233 & 1870 & & \\
\hline $44^{*}$ & & & & 168 & 1311 & & 10.8 & & 9.8 & & & & 191 & 1735 & & \\
\hline 45 & & 1068 & & 221 & & & 135 & & 15.2 & & & & & & 403 & \\
\hline 46 & & 872 & 180 & 1486 & 982 & & 231 & 1009 & & & 833 & & 3105 & 853 & & \\
\hline 47 & 232 & 340 & 40. & 1389 & 1276 & & 111 & & & & 784 & & 875 & & & \\
\hline 48 & 561 & & 283 & 189 & & 7.5 & 57 & 43 & 34.4 & 0.57 & & & 86 & & & \\
\hline
\end{tabular}

analyzed by external standard quantification, but samples marked with an asterisk were acidly digested followed by internal standard TXRF analysis. As can be compared from the obtained main compositions, samples from different manufacturers are significantly different.

Comparing the results in Table 1 and Table 2, we observe differences in the order of $10 \%$ for the acidly digested and external standard procedures.

In Figure 3 a characteristic TXRF spectrum of the sample 3GDP is shown. In this sample strong concentrations of elements such as $\mathrm{Ti}, \mathrm{W}, \mathrm{Fe}$, etc. are evaluated. The Ti and $\mathrm{W}$ are the most representative elements of the spectrum.

On the other hand, in Figure 4 the spectrum of sample GW_B is shown. A portion of the spectrum is enlarged in order to easily compare the abundance of many elements against the abundance of $\mathrm{Ti}$. In the enlarged area, small peaks can be seen representing the presence of arsenic and hafnium in this product. 


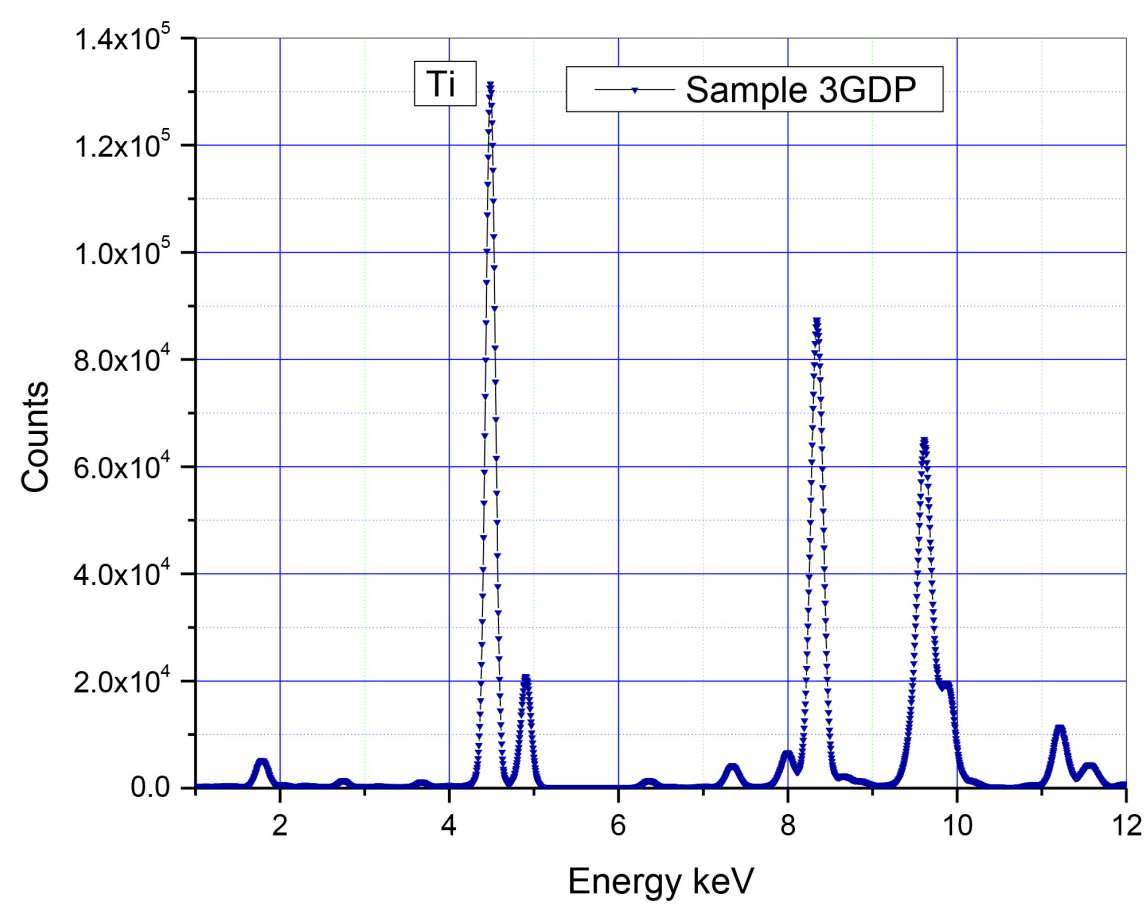

Figure 3. Characteristic TXRF spectrum of the sample 3GDP, where the Ti peak is clearly identified.

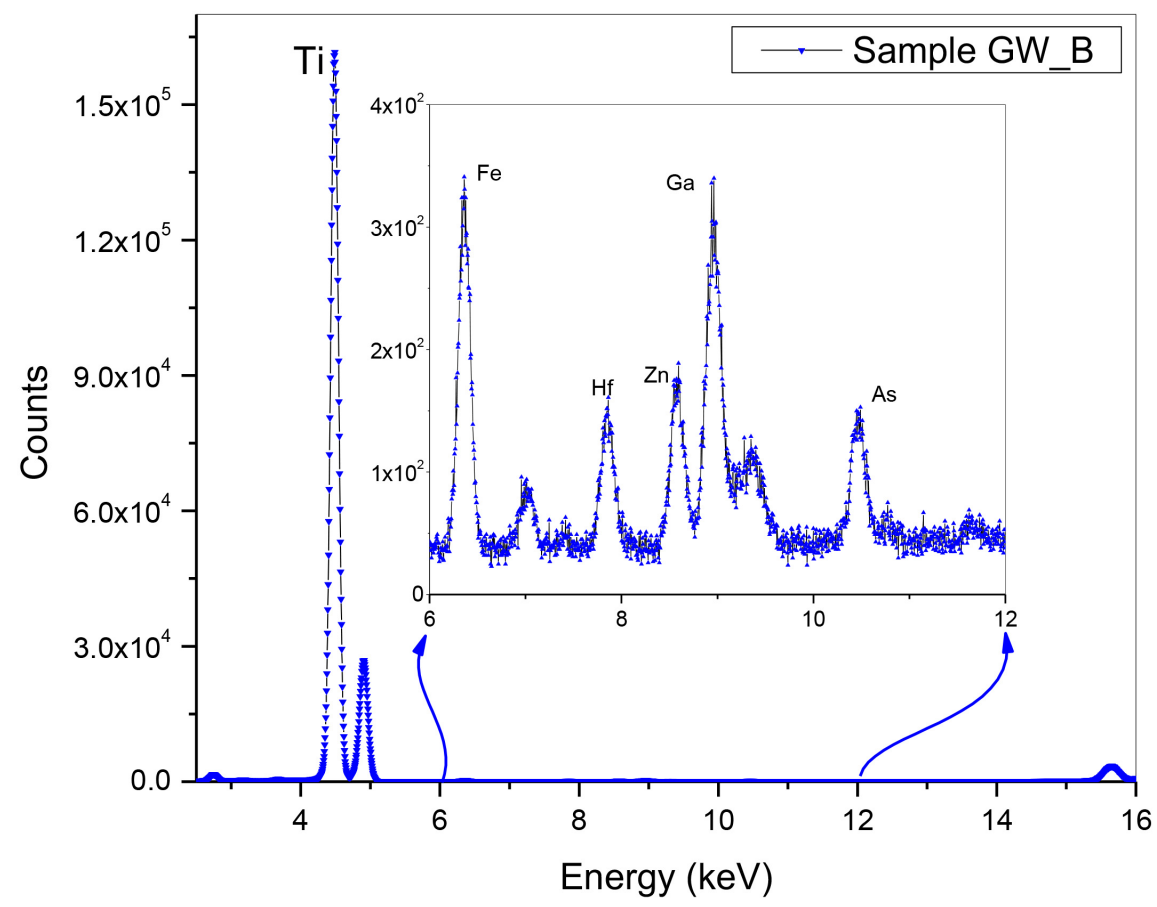

Figure 4. A characteristic TXRF spectrum of the sample GW_B, where a portion of the spectrum is enlarge in order to easily compare the abundance of many elements against the abundance of Ti.

\section{Discussions}

In this study we applied the TXRF technique for the evaluation of the inorganic 
composition of tattoo inks. The analysed samples consisted on 48 products (from 3 different suppliers) which can be classified in addition to colour in three different types, water based, oily based and alcohol based tattoo inks. Samples were freely acquired from on line suppliers, in Concepcion City, Chile.

All samples were analysed by external standard quantification, but in order to inter-compare the results, a $15 \%$ of the them were acidly digested and then quantified by the internal standard method. For external standard quantification we used very small specimens $(2 \mu \mathrm{L})$ in order to reduce effects over the morphology of the sample and over the excitation source. We replicated the methodology, previously applied for Cobalt evaluation in injectable multivitamins [37]. Comparing the results in Table 1 and Table 2, and in the previous study, for the particular kind of samples analysed, we obtain differences in the order of $10 \%$ between external standard quantification and acidly digested followed by internal standard quantification.

In the studied samples we evaluated the possible presence of harmful elements for human health. The results revealed that elemental content, and the seriousness of the results strongly varied among the manufacturers. Our results find much higher levels of Ti and W than those reported in Table A1 Refs. [9] [12] [13]. The Titanium quantification is very important since it is related to needle wear [39], producing particles containing $\mathrm{Cr}$ and Ni. These metals are classified as carcinogenic in humans and the latter is also an important sensitizer agent [27]. We also found As in many samples. However, the results are important only from the inorganic chemical profile of the samples. A complementary study should indicate if the most innocuous sets are also from the point of view of the organic components.

\section{Conclusions}

It is clear that the composition of the inks must be known and the substances contained in them must be harmless. Resolution ResAP (2008) 1 of the European Council Ref. [17] is the most important international standard that establishes limits and indicates components that should not be present in tattoo inks and permanent makeup. Studies have made the identification and quantification of hazardous chemical substances through various methodologies. In order to implement a regulatory framework, standardized analytical methods must be available for both, at national and international stages, taking into account the wide dissemination of the practice of tattooing and the serious problems for human health identified as a result of the composition of the inks.

This kind of studies would contribute to the identification of low-quality products on the market and assure a higher safety profile of tattoo compositions. Since the suppliers appear/disappear suddenly from any place of the world, the local governmental agencies must provide reliable import and export inspection and certification procedures for the tattoo inks. For that large number of analysis required, the TXRF technique is an excellent tool in order to obtain fast, mul- 
ti-elemental, simple and reliable results.

\section{Conflicts of Interest}

The authors declare no conflicts of interest regarding the publication of this paper.

\section{References}

[1] The Holy Bible (2011) Leviticus 19:28. International Standard Version (ISV). The ISV Foundation.

[2] Laumann, A. and Derick, A. (2006) Tattoos and Body Piercings in the United States: A National Data Set. Journal of the American Academy of Dermatology, 55, 413-421. https://doi.org/10.1016/j.jaad.2006.03.026

[3] Vasold, R., Engel, E., König, B., Landthaler, M. and Bäumler, W. (2008) Health Risks of Tattoo Colors. Analytical and Bioanalytical Chemistry, 391, 9-13. https://doi.org/10.1007/s00216-008-1978-Z

[4] (2015) El Tatuaje en el mundo y su relación con la Religión, E. Lopes da Silva, RUTA, No. 6.

[5] Ginechhi, L. (2012) El tatuaje religioso entre judíos, musulmanes y cristianos. TatooLife $n^{\circ} 75$, Ed. Mediafriendssrl, Milano.

[6] Los Chilenos Y Los Tatuajes, Microestudio GfKAdimark, 2017. http://www.adimark.cl/estudios/documentos/microestudio los $\% 20$ chilenos $\% 20 \mathrm{y} \% 2$ 0los\%20tatuajes.pdf

[7] Forte, G., Pretucci, F., Cristaudo, A. and Bocca, B. (2009) Quantification of Sensitizing Metals in Tattooing Pigments by SF-ICP-MS Technique. The Open Chemical and Biomedical Methods Journal, 2, 42-47. https://doi.org/10.2174/1875038900902020042

[8] Laux, P., et al. (2016) A Medical-Toxicological View of Tattooing. The Lancet, 387, 395-402. https://doi.org/10.1016/S0140-6736(15)60215-X

[9] Forte, G., Pretucci, F., Cristaudo, A. and Bocca, B. (2009) Market Survey on Toxic Metals Contained in Tattoo Inks. Science of the Total Environment, 407, 5997-6002. https://doi.org/10.1016/j.scitotenv.2009.08.034

[10] Kluger, N. and Koljonen, V. (2012) Tattoos, Inks, and Cancer. The Lancet Oncology, 13, 161-168.

[11] Silvestre, S. (2014) Aportación al Estudio de las tintas para tatuar. Revisión Bibliográfica. Máster Universitario en Técnicas Avanzadas de Estética y Láser. Universidad Cardenal Herrera, Valencia.

[12] Agencia de Protección Ambiental Danesa-Miljøstyrelsen (2012) Chemical Substances in Tattoo Ink: Survey of Chemical Substances in Consumer Products (Kortlægningafkemiskestoffer i forbrugerprodukter).

[13] Ministry of Health, New Zealand (2013) Survey of Selected Samples of Tattoo Inks for the Presence of Heavy Metals. Ministry of Health, Wellington.

[14] Environmental Protection Authority NZ-EPA (2012) Guidelines for Tattoo and Permanent Makeup Substances. Ministry of Health, Wellington.

[15] Tighe, M., Libby, D., Dorn, S., Hosmer, J. and Peaslee, G. (2017) A Survey of Metals Found in Tattoo Inks. Journal of Environmental Protection, 8, 1243-1253.

https://doi.org/10.4236/jep.2017.811077 
[16] Manso, M., et al. (2018) Assessment of Toxic Metals and Hazardous Substances in Tattoo Inks Using Sy-XRF, AAS, and Raman Spectroscopy. Biological Trace Element Research, 187, 596-601. https://doi.org/10.1007/s12011-018-1406-y

[17] Council of Europe (2018) ResAP(2008)1. On Requirements and Criteria for the Safety of Tattoos and Permanent Make-Up (Superseding Resolution ResAP (2003)2 on Tattoos and Permanent Make-Up).

[18] Regensburger, J., Lehner, K., Maisch, T., Vasold, R., Santarelli, F., Engel, E., Gollmer, A., König, B., Landthaler, M. and Baümler, W. (2010) Tattoo Inks Contain Polycyclic Aromatic Hydrocarbons That Additionally Generate Deleterious Singlet Oxygen. Experimental Dermatology, 19, 275-281. https://doi.org/10.1111/j.1600-0625.2010.01068.x

[19] Lehner, K., Santarelli, F., Vasold, R., König, B., Landthaler, M. and Bäumler, W. (2011) Black Tattoo Inks Are a Source of Problematic Substances Such as Dibutyl Phthalate. Contact Dermatitis, 65, 231-238. https://doi.org/10.1111/j.1600-0536.2011.01947.x

[20] Schreiver, I., Hutzler, C., Laux, P., Berlien, H.-P. and Luch, A. (2015) Formation of Highly Toxic Hydrogen Cyanide upon Ruby Laser Irradiation of the Tattoo Pigment Phthalocyanine Blue. Scientific Reports, 5, Article No. 12915.

https://doi.org/10.1038/srep12915

[21] Engel, E., Vasold, R., Santarelli, F., Maisch, T., Gopee, N., Howard, P., Landthaler, M. and Bäumler, W. (2010) Tattooing of Skin Results in Transportation and Light-Induced Decomposition of Tattoo Pigments-A First Quantification in Vivo Using a Mouse Model. Experimental Dermatology, 19, 54-60. https://doi.org/10.1111/j.1600-0625.2009.00925.x

[22] Morales-Callaghan, A., Aguilar-Bernier, M., Martínez-García, G. and MirandaRomero, A. (2006) Sarcoid Granuloma on Black Tattoo. Journal of the American Academy of Dermatology, 55, S71. https://doi.org/10.1016/j.jaad.2005.12.022

[23] Thum, C. and Biswas, A. (2015) Inflammatory Complications Related to Tattooing: A Histopathological Approach Based on Pattern Analysis. The American Journal of Dermatopathology, 37, 54-66. https://doi.org/10.1097/DAD.0b013e3182974558

[24] Rietschel, R. and Fowler, J. (2001) Contact Dermatitis and Other Reactions to Metals. In: Rietschel, R. and Fowler, J., Eds., Fisher's Contact Dermatitis, Williams \& Wilkins, Philadelphia, 86-89.

[25] Petersen, H. and Lewe, D. (2015) Chemical Purity and Toxicology of Pigments Used in Tattoo Inks. Current Problems in Dermatology, 48, 136-141. https://doi.org/10.1159/000369647

[26] Schubert, S. and Aberer, A. (2018) Allergic Reactions to Pigments, Metals, and More? Body Art from the Allergist's Point of View. In: De Cuyper, C. and PérezCotapos, M., Eds., Dermatologic Complications with Body Art, Springer, Cham, 57-58.

[27] International Agency for Research on Cancer IARC (2018) Agents Classified by the IARC Monographs, Volumes 1-121.

[28] Piccinini, P., Bianchi, I., Pakalin, S. and Senaldi, C. (2015) Safety of Tattoos and Permanent Make-Up: Compilation of Information on Legislative Framework and Analytical Methods. Joint Research Centre. European Commission.

[29] https://www.fda.gov/downloads/Cosmetics/ProductsIngredients/Products/UCM460 321.pdf

[30] https://www.minsal.cl/portal/url/item/c36871f580a44fc7e04001016501186c.pdf

[31] Markowicz, A.A. (1993) X-Ray Physics. In: Handbook of X-Ray Spectrometry: Me- 
thods and Techniques, Marcel Dekker Inc., New York, pages.

[32] Klockenkamper, R. (1996) Total-Reflection X-Ray Fluorescence Analysis. John Wiley \& Sons, Hoboken, 245.

[33] Bennun, L. and Sanhueza, V. (2010) A Procedure for the Improvement in the Determination of a TXRF Spectrometer Sensitivity Curve. Analytical Sciences, 26, 331-335. https://doi.org/10.2116/analsci.26.331

[34] Araneda, A., Sanhueza, V. and Bennun, L. (2016) Simplified Calibration for Total Reflection X-Ray Fluorescence. Analytical Letters, 49, 1711-1721. https://doi.org/10.1080/00032719.2015.1118486

[35] Horntrich, C., et al. (2011) Investigation of Element Distribution and Homogeneity of TXRF Samples Using SR-Micro-XRF to Validate the Use of an Internal Standard and Improve External Standard Quantification. Analytical and Bioanalytical Chemistry, 400, 2649-2654. https://doi.org/10.1007/s00216-010-4592-9

[36] Menzel, M., et al. (2015) Shading in TXRF: Calculations and Experimental Validation Using a Color X-Ray Camera. Journal of Analytical Atomic Spectrometry, 30, 2184-2193. https://doi.org/10.1039/C5JA00127G

[37] Riffo, G., Ramírez-Lama, C., Agüero, L. and Bennun, L. (2018) Quantification of Vitamin B12 Content in Multivitamins and Elements in Mineral Supplements in Chile, by Total Reflection X-Ray Fluorescence. International Journal of Pharmaceutical Sciences and Research, 9, 3678-3688. https://doi.org/10.13040/IJPSR.0975-8232

[38] Floora, G.H., Queralt, I., Hidalgo, M. and Marguí, E. (2015) Measurement Uncertainty in Total Reflection X-Ray Fluorescence. Spectrochimica Acta Part B: Atomic Spectroscopy, 111, 30-37. https://doi.org/10.1016/j.sab.2015.06.015

[39] Schreiver, et al. (2019) Distribution of Nickel and Chromium Containing Particles from Tattoo Needle Wear in Humans and Its Possible Impact on Allergic Reactions. Particle and Fibre Toxicology, 16, 47-52. https://doi.org/10.1186/s12989-019-0317-1 
Appendix 1. A Small Compilation of Information Related to the Tattoo Inks Inorganic and Organic Components

Table A1. Maximum elemental concentrations found in tattoo inks.

\begin{tabular}{|c|c|c|}
\hline Element & Concentration $(\mu \mathrm{g} / \mathrm{g})$ & Reference \\
\hline $\mathrm{Fe}$ & 88,443 & 1 \\
\hline $\mathrm{Cu}$ (soluble) & 32,900 & 3 \\
\hline $\mathrm{Ba}$ & 17,000 & 3 \\
\hline $\mathrm{Ca}$ & 16,000 & 3 \\
\hline $\mathrm{Al}$ & 11,000 & 2 \\
\hline $\mathrm{Na}$ & 5800 & 2 \\
\hline $\mathrm{Zr}$ & 2800 & 2 \\
\hline $\mathrm{Mg}$ & 1700 & 2 \\
\hline $\mathrm{Zn}$ & 1640 & 3 \\
\hline $\mathrm{Ti}$ & 960 & 2 \\
\hline $\mathrm{K}$ & 680 & 2 \\
\hline $\mathrm{Cr}$ & 147 & 1.3 \\
\hline $\mathrm{Sb}$ & 147 & 3 \\
\hline $\mathrm{Mn}$ & 99 & 1.3 \\
\hline As & 60 & 3 \\
\hline $\mathrm{Pb}$ & 45 & 3 \\
\hline $\mathrm{Hf}$ & 38 & 2 \\
\hline $\mathrm{Sr}$ & 36 & 1 \\
\hline $\mathrm{Ni}$ & 23 & 4 \\
\hline $\mathrm{Pd}$ & 21 & 2 \\
\hline $\mathrm{Ag}$ & 11 & 2 \\
\hline $\mathrm{V}$ & 11 & 1 \\
\hline Co & 6.4 & 1 \\
\hline $\mathrm{La}$ & 4.8 & 2 \\
\hline $\mathrm{Rb}$ & 4.2 & 2 \\
\hline $\mathrm{Y}$ & 4.1 & 2 \\
\hline Sn & 4.1 & 2 \\
\hline $\mathrm{Cd}$ & 2.9 & 1 \\
\hline $\mathrm{Ce}$ & 2.8 & 2 \\
\hline Mo & 2.4 & 2 \\
\hline $\mathrm{Li}$ & 2.2 & 2 \\
\hline $\mathrm{Se}$ & 2.0 & 3 \\
\hline Th & 1.5 & 2 \\
\hline $\mathrm{Ga}$ & 1.1 & 2 \\
\hline $\mathrm{Nb}$ & 0.80 & 2 \\
\hline Sc & 0.54 & 2 \\
\hline Cs & 0.43 & 2 \\
\hline
\end{tabular}




\section{Continued}

\begin{tabular}{|c|c|c|}
\hline $\mathrm{W}$ & 0.32 & 2 \\
\hline $\mathrm{Nd}$ & 0.31 & 2 \\
\hline $\mathrm{Pt}$ & 0.30 & 2 \\
\hline $\mathrm{Bi}$ & 0.28 & 2 \\
\hline $\mathrm{Hg}$ & 0.25 & 1 \\
\hline $\mathrm{U}$ & 0.14 & 2 \\
\hline $\mathrm{Eu}$ & 0.12 & 2 \\
\hline Gd & 0.10 & 2 \\
\hline $\mathrm{Sm}$ & 0.087 & 2 \\
\hline Dy & 0.082 & 2 \\
\hline $\operatorname{Pr}$ & 0.079 & 2 \\
\hline $\mathrm{Yb}$ & 0.053 & 2 \\
\hline $\mathrm{Au}$ & 0.045 & 2 \\
\hline $\mathrm{Ta}$ & 0.044 & 2 \\
\hline Er & 0.043 & 2 \\
\hline $\mathrm{Tl}$ & 0.039 & 2 \\
\hline In & 0.014 & 2 \\
\hline $\mathrm{Lu}$ & 0.010 & 2 \\
\hline
\end{tabular}

Source: ${ }^{1}$ Forte et al. (2009a) Ref. [9], ${ }^{2}$ Danish Environmental Protection Agency (2012), Ref. [12]. ${ }^{3}$ Ministry of Health, New Zealand (2013), Ref. [13].

Table A2. Maximum concentrations of Polycyclic Aromatic Hydrocarbons (PAHs) found in tattoo inks.

\begin{tabular}{cc}
\hline PAH & Concentration $(\mu \mathrm{g} / \mathrm{g})$ \\
\hline Phenanthrene & $24.5 \pm 6.0$ \\
Acenaphylene & $14.5 \pm 5.5$ \\
Benzo (b) fluorantene & $4.5 \pm 4.3$ \\
Pyrene & $28 \pm 1.0$ \\
Anthracene & $3.3 \pm 0.8$ \\
Fluorantene & $7.5 \pm 0.1$ \\
Chrysane & $1.7 \pm 0.8$ \\
Benzo (a) anthracene & $1.6 \pm 0.2$ \\
Benzo (g, h, i) perylene & $5.6 \pm 0.2$ \\
Indene (1,2,3-c, d) pyrene & $1.1 \pm 1.0$ \\
Acenafteno & $1.7 \pm 0.1$ \\
Fluorene & $0.9 \pm 0.2$ \\
Benzo (k) fluorantene & $1.0 \pm 0.2$ \\
Benzo (a) pyrene & $5.3 \pm 0.9$ \\
Naphthalene & $81 \pm 25$ \\
Dibenzo (a, h) anthracene & $0.19 \pm 0.02$ \\
\hline
\end{tabular}

Source: Danish Environmental Protection Agency (2012), Ref. [12]; Regensburger et al. (2010) Ref. [18]. 
Table A3. Classification of tattoo ink components according to the International Agency for Research on Cancer.

\begin{tabular}{|c|c|}
\hline Component & Group IARC \\
\hline \multicolumn{2}{|l|}{ Metals } \\
\hline Arsenic and its inorganic compounds & 1 \\
\hline Beryllium and its compounds & 1 \\
\hline Cadmium and its compounds & 1 \\
\hline Nickel and its compounds & 1 \\
\hline Component & IARC Group \\
\hline Chrome (VI) compounds & 1 \\
\hline Lead, inorganic compounds & $2 \mathrm{~A}$ \\
\hline Cobalt and its compounds & $2 \mathrm{~B}$ \\
\hline Lead & $2 \mathrm{~B}$ \\
\hline Titanium dioxide PAA & $2 \mathrm{~B}$ \\
\hline Anisidine & 1 \\
\hline Nitro-o-Toluidine & $2 \mathrm{~A}$ \\
\hline Cloro-o-toluidina & $2 \mathrm{~A}$ \\
\hline 3,3 dichlorobenzidine $\mathrm{PAH}$ & $2 \mathrm{~B}$ \\
\hline Benzo Pyrenees & 1 \\
\hline Benzo anthracene & $2 \mathrm{~A}$ \\
\hline Dibenzo [ah] anthracene & $2 \mathrm{~A}$ \\
\hline Benzo (k) fluorantene & $2 \mathrm{~B}$ \\
\hline Benzo (b) fluorantene & $2 \mathrm{~B}$ \\
\hline Chrysane & $2 \mathrm{~B}$ \\
\hline Naphthalene & $2 \mathrm{~B}$ \\
\hline Black carbon & $2 \mathrm{~B}$ \\
\hline
\end{tabular}

Source: IARC (2018) Ref. [27].

Table A4. Maximum permitted concentrations of impurities in products for tattoos and permanent makeup.

\begin{tabular}{cc}
\hline Element or compound & Concentration $(\mu \mathrm{g} / \mathrm{g})$ \\
\hline Arsenic $(\mathrm{As})$ & 2 \\
Barium $(\mathrm{Ba})$ & 50 \\
Cadmium $(\mathrm{Cd})$ & 0.2 \\
Cobalt $(\mathrm{Co})$ & 25 \\
Chrome $(\mathrm{Cr})(\mathrm{VI})$ & 0.2 \\
Copper (Cu) soluble & 25 \\
Mercury (Hg) & 0.2 \\
Nickel (Ni) & 2 \\
Lead (Pb) & 2 \\
Selenium (Se) & 2 \\
Antimony $(\mathrm{Sb})$ & 50 \\
Tin $(\mathrm{Sn})$ & 50 \\
Zinc $(\mathrm{Zn})$ & \\
\hline
\end{tabular}

Source: ResAP (2008) Ref. [17]. 